Article

\title{
Entomological Assessment of Onchocerca Species Transmission by Black Flies in Selected Communities in the West Region of Cameroon
}

\author{
Cabirou Mounchili Shintouo ${ }^{1,2,3}$, Joel Ebai Nguve ${ }^{3}$, Fru Bertha Asa ${ }^{4}$, Robert Adamu Shey ${ }^{3,5}$, \\ Joseph Kamga ${ }^{3}$, Jacob Souopgui ${ }^{5, *,+} \mathbb{D}$, Stephen Mbigha Ghogomu ${ }^{3, *,+} \mathbb{C}$ and \\ Rose Njemini ${ }^{1,2, *,+(D)}$ \\ 1 Department of Gerontology, Faculty of Medicine and Pharmacy, Vrije Universiteit Brussel, Laarbeeklaan 103, \\ B-1090 Brussels, Belgium; Cabirou.Mounchili.Shintouo@vub.be \\ 2 Frailty in Ageing Research Group, Vrije Universiteit Brussel, Laarbeeklaan 103, B-1090 Brussels, Belgium \\ 3 Department of Biochemistry and Molecular Biology, Faculty of Science, University of Buea, Buea P.O. Box 63, \\ Cameroon; joelebai@gmail.com (J.E.N.); robeshey@ulb.ac.be (R.A.S.); josephkamga69@yahoo.fr (J.K.) \\ 4 Department of Public Health and Hygiene, Faculty of Health Science, University of Buea, \\ Buea P.O. Box 63, Cameroon; bertizi.ba@gmail.com \\ 5 Department of Molecular Biology, Institute of Biology and Molecular Medicine, IBMM, Universite Libre de \\ Bruxelles, Gosselies Campus, 126040 Gosselies, Belgium \\ * Correspondence: jsouopgu@ulb.ac.be (J.S.); stephen.ghogomu@ubuea.cm (S.M.G.); \\ Rose.Njemini@vub.be (R.N.); Tel.: +32-265-099-36 (J.S.); +237-678-455-646 (S.M.G.); +32-247-742-41 (R.N.) \\ + These authors are last authors on this work.
}

Received: 13 August 2020; Accepted: 31 August 2020; Published: 2 September 2020

\begin{abstract}
The enormity of the public health burden of onchocerciasis motivated the creation of various large-scale control programs that have depended principally on mass treatment of endemic communities with ivermectin for the elimination of the disease. Parasitological evaluation of Onchocerca species in the West Region of Cameroon indicates significant progress in the interruption of parasite transmission in some communities under ivermectin treatment. However, to verify the complete elimination of onchocerciasis, entomological assessment through O-150 PCR poolscreen of black flies is mandatory. Thus, in the present study, we assessed transmission of Onchocerca species using an O-150 PCR technique to screen pools of black flies-in seven onchocerciasis endemic communities (Makouopsap, Bankambe, Lemgo, Tsesse, Ndionzou, Kouffen, and Bayon) in Cameroon. Two thousand black flies were assessed-in each community—for the presence of Onchocerca species DNA. Our results show that the frequency of infective flies was $0.6 \%$ in Makouopsap and $0.0 \%$ in the other communities. On the other hand, the frequency of infected flies was $0.8 \%$ in Makouopsap, $0.2 \%$ in Bankambe, $0.1 \%$ in Bayon, and $0.0 \%$ in Lemgo, Tsesse, Ndionzou, and Kouffen. These results provide entomologic evidence for continuous transmission of Onchocerca species in Makouopsap, risk of active transmission in Bankambe, and Bayon, and a suppressed transmission in the four other studied communities.
\end{abstract}

Keywords: onchocerciasis; ivermectin; O-150 PCR; poolscreen; elimination

\section{Introduction}

Human onchocerciasis, also known as river blindness, is a filarial disease caused by the parasite Onchocerca volvulus (O. volvulus) and is one of the most debilitating yet neglected tropical diseases [1]. The infective larvae (L3) are transmitted through the repeated bites of infective black flies (Simulium), which eventually give rise to adult worms. The latter dwell in subcutaneous tissues in humans where 
they can survive for about 15 years under drug pressure, with adult females hatching about 1600 microfilariae daily [2]. The microfilariae migrate through the skin where they can be ingested by a black fly during a blood meal. Once ingested, the microfilaria migrates to the thoracic muscles of the black fly where it develops into the first (L1) and second (L2) larval stages, and the black fly becomes infected. The L2 larva subsequently develops into the L3 stage, which migrates to the black fly's proboscis rendering it infective and, as such, the fly can infect humans when taking a blood meal [3]. On the other hand, Onchocerca ochengi (O. ochengi), a bovine parasite of Zebu cattle in Africa is the closest related species to $O$. volvulus and both parasites are transmitted by the same black fly vector [4]. Whereas $O$. ochengi causes little harm in its cattle host, the microfilariae of $O$. volvulus induce considerable pathology in humans [5]. The O. volvulus microfilariae cause persistent itching, severe skin diseases, and frequently induce ocular lesions that may result in a progressive loss of vision and blindness [6]. In 2017, about 20.9 million persons were infected with human onchocerciasis worldwide, with 1.15 million having vision loss, 14.6 million having a skin disease, and more than $99 \%$ living in Africa [7]. In Cameroon where this study was conducted, 2.8 million people are infected by the disease and 5.2 million people are at risk of infection [8], making the disease an important public health concern.

To mitigate the public health and socio-economic burden of onchocerciasis, various large-scale control programs - through Community Directed Treatment with Ivermectin (CDTI) - have been implemented in onchocerciasis endemic regions in Africa [9]. In the West Region of Cameroon, treatment started in 1996-with the support of the Carter Center and Lions Club International Foundation-as a community-based treatment with an annual dose of ivermectin [10]. This CDTI program in the West Region of Cameroon was evaluated by the World Health Organization (WHO) and the African Program for Onchocerciasis Control (APOC) in 2011, and the results of the survey revealed a microfilaria prevalence of $38.6 \%$ [11]. Therefore, the conduction of additional surveys at intervals of three to four years was highly recommended. In this framework, Kamga et al. [12], repeated the survey in 2015 and concluded that, with the exception of Makouopsap, there was an important progress in parasite transmission interruption in the communities surveyed. However, to guarantee complete elimination of onchocerciasis, poolscreen testing of black flies is strongly recommended by WHO [13].

In the current study, we aimed to further evaluate the progress made towards eliminating onchocerciasis transmission in the West Region of Cameroon, by focusing on the entomological assessment of Onchocerca species (Onchocerca spp.) transmission by black flies using a O-150 PCR (Poolscreen) technique in selected communities under ivermectin treatment for the past two decades.

\section{Results}

\subsection{Percentage of Infective and Infected Pools of Black Flies in Surveyed Communities}

In order to investigate if transmission of onchocerciasis is ongoing in the West Region of Cameroon, we carried out PCR analysis to assess Onchocerca parasites in black flies. Individual black flies were collected in seven communities located in different health districts in the region. The WHO 2016 guidelines for verification of onchocerciasis elimination recommend that a minimum of 6000 black flies must be collected from a transmission zone [13]. Accordingly, in each surveyed community, 2000 black flies were collected giving a total of 14,000 black flies in the transmission zone that we studied. The black flies were collected before ivermectin was distributed in each community by the West Onchocerciasis Control Program. When the required total of 2000 black flies were reached, the collection of flies in the community was stopped. On average, the effective period of fly-catching in each community was five days. The black flies were grouped into pools of 200, separated into heads and bodies giving a total of 10 head pools of 200 heads and 10 body pools of 200 bodies per community. DNA was extracted from each pool and tested for the presence of Onchocerca spp. specific DNA using an O-150 PCR assay. End-point agarose electropherogram PCR of positive samples showed three sharp bands (Figure 1) characteristic of the presence of Onchocerca spp. DNA in the pools of black flies 
analyzed [14]. Amplification via in silico PCR (http://insilico.ehu.eus/), predicted that each band has a length of $147 \mathrm{bp}$ with the first, second, and third bands at positions 1, 298, and 595, respectively, of the Onchocerca spp. repetitive sequence DNA (GenBank: J04659.1). Following the processing and analysis of all the collected black fly samples, we found that the percentage of infective pools was $70 \%$ in Makouopsap, and $0 \%$ in all the other communities while the percentage of infected pools was $80 \%, 30 \%$, and 20\% in Makouopsap, Bankambe, and Bayon, respectively, and $0 \%$ in Lemgo, Tsesse, Ndionzou, and Kouffen (see Figure 2).

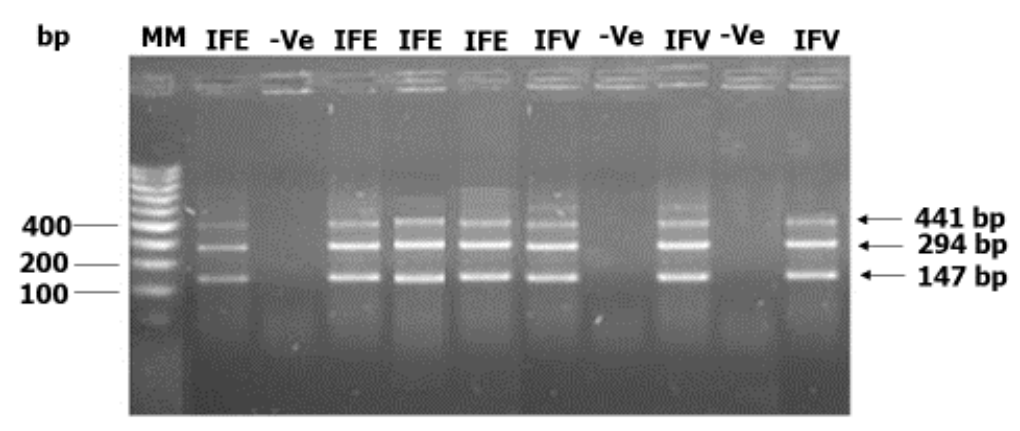

Figure 1. PCR analysis of infective and infected black fly pools in Makouopsap. The PCR products were amplified using specific sets of primers. The amplified PCR products were separated on $2 \%$ agarose gels and visualized under UV light. MM = Molecular weight maker, IFE = Infected pool, IFV $=$ Infective pool,$-\mathrm{Ve}=$ Negative pool, and $b p=$ base pair.

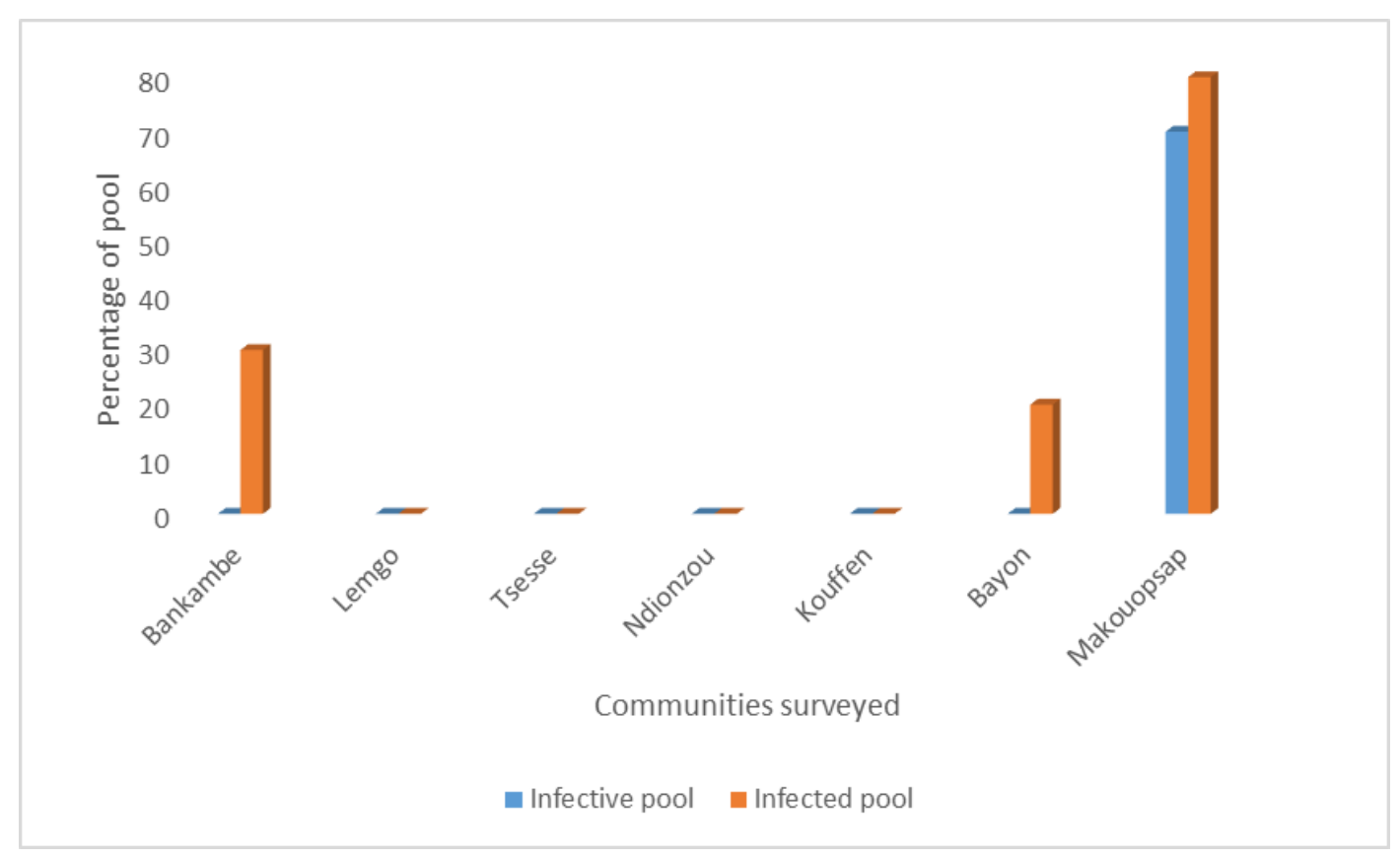

Figure 2. Summary of infective and infected pools of black flies in the surveyed communities. The percentage of the infective and infected pools of black flies were gotten from the agarose gel electropherogram of an O-150 PCR assay. Overall, $7(10 \%)$ and $13(18.6 \%)$ of the pools were infective and infected, respectively. Although there was a significant variation in infective status of black flies across the communities $(p<0.001)$, the community of sampling was not a significant risk factor $(p=0.992)$ for the infective status of black flies overall following logistic regression analysis. However, the community of sampling was a significant risk factor for infected status of black flies $(p=0.007)$. 


\subsection{Frequency of Infective and Infected Black Flies}

The frequency of the infective and infected black flies-taken from pools of black fly heads and bodies, respectively - were determined using the Poolscreen algorithm. Our findings revealed that the frequency of infective black flies was $0.6 \%$ (95\% CI 0.00216-0.01347) in Makouopsap and $0.0 \%(95 \%$ CI $0-0.00096)$ in the other communities. On the other hand, the frequency of infected black flies was $0.8 \%$ (95\% CI 0.00303-0.1809) in Makouopsap, 0.2\% (95\% CI 0.00034-0.00521) in Bankambe, $0.1 \%$ (95\% CI 0.00131-0.00393) in Bayon, and 0.0\% (95\% CI 0-0.00096) in Lemgo, Tsesse, Ndionzou, and Kouffen (see Table 1).

Table 1. Frequency of infective and infected black flies determined by the Poolscreen algorithm with 95\% Confidence Interval (CI) in pools of 200 black flies.

\begin{tabular}{|c|c|c|c|c|}
\hline \multirow[b]{2}{*}{ Community } & \multicolumn{2}{|c|}{ Infective Pool } & \multicolumn{2}{|c|}{ Infected Pool } \\
\hline & Frequency & $\begin{array}{l}\text { 95\% Confidence } \\
\text { Interval }^{\text {a }}\end{array}$ & Frequency & $\begin{array}{l}\text { 95\% Confidence } \\
\text { Interval }^{\text {a }}\end{array}$ \\
\hline Bankambe & 0.0 & $0-0.00096$ & 0.2 & $0.00034-0.00521$ \\
\hline Lemgo & 0.0 & $0-0.00096$ & 0.0 & $0-0.00096$ \\
\hline Tsesse & 0.0 & $0-0.00096$ & 0.0 & $0-0.00096$ \\
\hline Ndionzou & 0.0 & $0-0.00096$ & 0.0 & $0-0.00096$ \\
\hline Kouffen & 0.0 & $0-0.00096$ & 0.0 & $0-0.00096$ \\
\hline Bayon & 0.0 & $0-0.00096$ & 0.1 & $0.00131-0.00393$ \\
\hline Makouopsap & 0.6 & $0.00216-0.01347$ & 0.8 & $0.00303-0.1809$ \\
\hline
\end{tabular}

\section{Discussion}

This study was motivated by the fundamental lack of information as to whether or not mass drug administration (MDA) should be stopped in previously onchocerciasis-endemic communities in the West Region of Cameroon that have been under MDA with ivermectin for the past two decades. To carry out an evaluation of the impact of continuous chemotherapy on the presence of Onchocerca spp. detected in black flies, seven communities were chosen based on recent reports [12]. Our findings provide entomological evidence for continuous transmission of Onchocerca spp. in Makouopsap and suggests the need to review current CDTI strategies and the need for O. volvulus specific entomological assessments to inform the national program.

The frequency of infective and infected black flies was 0.0\% (95\% CI 0-0.00096) in Lemgo, Tsesse, Ndionzou, and Kouffen. As per the WHO guidelines, in order to confirm interruption of onchocerciasis transmission - for a total of 2000 black flies-the upper bound of the $95 \%$ confidence interval of the prevalence of infective black flies should be less than $0.05 \%$, which is equivalent to one infected black fly per 2000 black flies. Moreover, a minimum of 6000 black flies should be collected from a transmission zone and all should be free of infective larvae to ensure that the upper bound of the $95 \%$ confidence interval is met [13]. Accordingly, in the present study, a total of 2000 black flies were examined in each community making a total of 14,000 flies from the transmission zone. The results therefore indicate that there is no ongoing transmission of the disease in Lemgo, Tsesse, Ndionzou, and Kouffen and that Onchocerca parasites are absent in humans as well as in the cattle population in these communities. These findings are in accordance with the report of Kamga et al. [12], which portrayed a microfilaridermia prevalence of $0 \%$ in humans in these communities. Notwithstanding, the entomological evaluation of all neighboring communities is needed before discontinuing annual MDA in these communities to avoid recrudescence of the disease as was the case in Burkina Faso [15]. In this perspective, the use of the Ov-16 serology test to detect exposure to the O. volvulus parasite in children below 10 years is highly recommended [16]. 
There were no infective black flies in Bankambe and Bayon while the percentage of infected black fly pools was $30 \%$ and $20 \%$, respectively. Moreover, the frequency of infective black flies was $0.0 \%$ (95\% CI 0-0.0096) in both communities while the frequency of infected black flies was $0.2 \%(95 \% \mathrm{CI}$ 0.00034-0.00521) in Bankambe and 0.1\% (95\% CI 0.00131-0.00393) in Bayon. These results indicate that the transmission of onchocerciasis has been interrupted in these communities considering that the presence of Onchocerca parasites in black fly bodies does not necessarily imply current transmission, which usually requires the presence of infective L3 stage larvae in the head of the fly [13]. The body of black flies, which may contain Onchocerca spp. DNA from microfilaria or L2 stages, is used to evaluate the presence of the parasites in humans and cattle $[5,13]$. Therefore, the frequency of $0.2 \%$ and $0.1 \%$ of infected black flies-respectively obtained in Bankambe and Bayon-indicates that the parasite is present in the human and/or cattle population. This is in line with the findings of Kamga et al. [12], that reported a microfilaridermia prevalence of $2.6 \%$ and 2.3\% in humans in Bankambe and Bayon, respectively. Thus, these findings suggest that ivermectin distribution should continue.

In Makouopsap, the percentage of infective and infected black fly pools were $70 \%$ and $80 \%$, respectively, with a frequency of $0.6 \%$ (95\% CI $0.00216-0.01347)$ and $0.8 \%$ (95\% CI $0.00303-0.1809)$, respectively. These results indicate that transmission of onchocerciasis is ongoing in Makouopsap, and this is supported by the high prevalence of nodules and microfilaria reported by others [12,17]. The high frequency of onchocerciasis in Makouopsap may be due to suboptimal responses to ivermectin as was observed in some onchocerciasis endemic areas in the South West Region of Cameroon and Ghana $[8,18]$. Another possible explanation for the high frequency of the disease could be related to reinfection across the neighboring Center Region, where there are reports of considerable onchocerciasis transmission $[19,20]$. Therefore, a collaboration between the regions to harmonize intervention strategy is needed in order to reach the goal of eliminating onchocerciasis transmission. Additionally, new strategic options and alternative treatment strategies should be implemented to accelerate the elimination of onchocerciasis transmission in Makouopsap. A probable elimination strategy could be the use of bi-annual MDA of ivermectin as was suggested by APOC [21]. This strategy successfully interrupted the transmission of O. volvulus in the Abu Hamed focus in Sudan [22]. Taken together, there is a need for the development of new treatment strategies to combat this disease in order to achieve the goal of elimination $[23,24]$.

The authors acknowledge the limitation of not using O. volvulus-specific DNA probes to detect O. volvulus. Indeed, it has been mentioned that the use of O. volvulus-specific DNA probes guarantees absolute specificity and allows for processing large numbers of black flies; thereby, increasing the reliability of the results [25]. The entomological evidence reported herein reveals that there is on-going transmission of onchocerciasis in Makouopsap. However, since O. volvulus specific DNA probes were not employed, there is a possibility that some of the parasites found in the black flies could be O. ochengi, as was reported in the North Region of Cameroon [26]. Notwithstanding, the high proportion of individuals infected with $O$. volvulus as reported by Kamga et al. [12], do suggest that the majority of the black flies may be infected with $O$. volvulus.

Another limitation of this study is that it did not cover all the onchocerciasis endemic communities in the West Region of Cameroon. Our near-future goal is to use the O.volvulus-specific DNA probes to detect $O$. volvulus in samples from the other endemic communities of the transmission zone. Although this study has some limitations, it addresses a gap in the literature. Thus far, the scant data on the West Region of Cameroon CDTI program have not addressed entomological indices. Our attempt to detect Onchocerca spp. DNA in black flies offers insight into the entomological profile of onchocerciasis transmission in the West Region of Cameroon and makes our study complementary to previous parasitological studies that were carried out in the region.

\section{Conclusions}

The data presented demonstrate that the CDTI strategy for the treatment of onchocerciasis in Cameroon has made progress towards the elimination of transmission of this disease in Lemgo, Tsesse, 
Ndionzou, Kouffen, Bankambe, and Bayon. Transmission of onchocerciasis is ongoing in Makouopsap, and to reach the goal of interrupting transmission completely, it will be necessary for the program to adopt new strategic options and alternative treatment strategies.

\section{Materials and Methods}

\subsection{Ethical Considerations and Participant Enlistment}

The study was approved by the Cameroon Bioethics Initiative (CAMBIN) Ethics Review and Consultancy Committee (ERCC) $\left(\mathrm{N}^{\circ} \mathrm{CBI} / 443 / \mathrm{ERCC} / \mathrm{CAMBIN}\right)$. Administrative authorization was obtained from the Cameroon Ministry of Public Health ( $\left.\mathrm{N}^{\circ} 631-1315\right)$. Written informed consent forms were distributed and well explained to all black fly collectors. All the black fly collectors, who were indigenes of the respective studied communities, voluntarily signed and returned the consent form before participation in the study. Ivermectin was administered to all black fly collectors one week prior to the start of collection.

\subsection{Selection of Study Sites and Black Fly Collection}

This study was conducted in seven communities in the West Region of Cameroon located in the same transmission zone. As per the WHO guidelines, a transmission zone is a geographical area where transmission of $O$. volvulus occurs by locally breeding vectors and which can be regarded as a natural ecological and epidemiological unit for interventions [13]. The black flies were identified by an entomologist based on the morphological characters used for the identification of black fly species: the color of the scutellum, wing tufts and arculus of the antennae, the procoxa, and the ninth abdominal tergit [27]. The black fly species in the area was the Simulium squamosum, which belongs to the forest cytospecies. Entomological collections were conducted during the peak transmission period of August through November 2019 in Makouopsap, Bankambe, Bayon, Lemgo, Tsesse, Ndionzou, and Kouffen (see Figure 3)-located in 6 out of the 20 health districts of the West Region of Cameroon $\left(5^{\circ} 30^{\prime} 0^{\prime \prime} \mathrm{N}\right.$, $10^{\circ} 30^{\prime} 0^{\prime \prime} \mathrm{E}$ ) - based on recent reports on parasitological findings in humans after 21 years of CDTI in these communities [12]. In principle, all the 15 communities were planned for testing since they all shared the same vector. However, we decided to start with six communities that were reported to be near elimination and one which is hyperendemic as a control (see Table 2). The communities were considered first line because they are found near the breading site of the vector. Treatment of onchocerciasis in these communities is done yearly in August [28], but with delays, treatment can span through the whole peak transmission period. The standard human landing capture method [29] was used to obtain 2000 black flies during daytime in each surveyed community. Briefly, the black fly catchers were separated into groups composed of one human bait and two collectors. The human baits wore black long thick socks that cover their entire legs and sat on higher stools while the collectors sat on lower stools and wait for flies to land on the lower limbs of the baits. Once a black fly lands on a bait, the collector covers it with a tube and captures it as it tries to escape. The collector covers the tube with the finger and quickly puts the cork mesh and then the cork on the tube to trap the black fly. All black flies showing evidence of a recent blood meal were discarded. Black flies caught were drowned for 2 min using a drowning solution ( $250 \mu$ L Kodak PhotoFlo-200 and $500 \mathrm{~mL} 1 \times$ PBS) and transferred to a cleaning solution $(500 \mu \mathrm{L}$ Tween-80, $500 \mu \mathrm{L} 5 \%$ Clorox, $10 \mathrm{~mL} 100 \times \mathrm{PSF}$, and $489 \mathrm{~mL}$ $1 \times$ PBS). The black flies were then stored in 100\% iso-propanol in pools of 200 at room temperature [30] until transported to the Molecular and Cell Biology laboratory (MCBL) of the University of Buea, Cameroon. The preserved black fly pools were then placed in liquid nitrogen and subjected to vigorous agitation to separate the heads from the bodies. The heads were collected by sieving through 25 mesh size sieves. The mesh has been reported to be effective in separating black fly bodies and heads without cross contamination [30-32]. Additionally, a clean separation was verified using a dissection microscope (Olympus, Tokyo, Japan) and the heads and bodies were stored separately in pools of 200 each at $-80^{\circ} \mathrm{C}$. 
Table 2. Prevalence of O. volvulus microfilaria in selected communities in 2015.

\begin{tabular}{ccccc}
\hline Health District & Community & $n$ & Mf $+(n)$ & Microfilaria Prevalence (\%) \\
\hline Bafang & Bankambe & 203 & 9 & 2.6 \\
\hline \multirow{2}{*}{ Bandjoun } & Lemgo & 75 & 0 & 0.0 \\
\cline { 2 - 5 } & Tsesse & 123 & 0 & 0.0 \\
\hline Bangangté & Ndionzou & 141 & 0 & 0.0 \\
\hline Foumbot & Kouffen & 107 & 0 & 0.0 \\
\hline Kékem & Bayon & 231 & 6 & 2.3 \\
\hline Massangam & Makouopsap & 123 & 53 & 41.6
\end{tabular}

Microfilaria prevalence in the surveyed communities after 21 years of CDTI [12]. $n=$ number examined, Mf + $(n)=$ number with microfilaria positive skin snip.

\subsection{DNA Extraction}

The pool of samples was rinsed three times in $95 \%$ ethanol. Thereafter, separated heads and bodies were frozen in liquid nitrogen and macerated with pestles. DNA was extracted from each pool using Maxwell S3000 robot (Promega Co., Madison, WI, USA) and the Maxwell ${ }^{\circledR}$ RSC Pure food, GMO, and Authentication kit (Promega Co., Madison, WI, USA) according to manufacturer's instruction. Briefly, $600 \mu \mathrm{L}$ of CTAB Buffer, $2 \mu \mathrm{L}$ of RNase A and $30 \mu \mathrm{L}$ of Proteinase K were added to a $1.5 \mathrm{~mL}$ microcentrifuge tube containing $200 \mathrm{mg}$ of sample. The samples were incubated at $60^{\circ} \mathrm{C}$ for $30 \mathrm{~min}$ and centrifuged at room temperature for $10 \mathrm{~min}$ at 13,000 RPM. Thereafter, $300 \mu \mathrm{L}$ of clear lysate sample was transferred to the reagent cartridge which was placed in the Maxwell ${ }^{\circledR} 16$ for automated DNA purification. This technique has been used to extract DNA from samples of diverse origin including black flies [31,33-35]. Moreover, the sensitivity and relative effectiveness of the method was evaluated in comparison with the phenol chloroform method-gold standard of DNA extraction for entomological surveillance in Latin America-for the detection of O. volvulus in pools of black flies, with results indicating that the automated method is as sensitive as phenol chloroform method, nontoxic, and rapid [31].

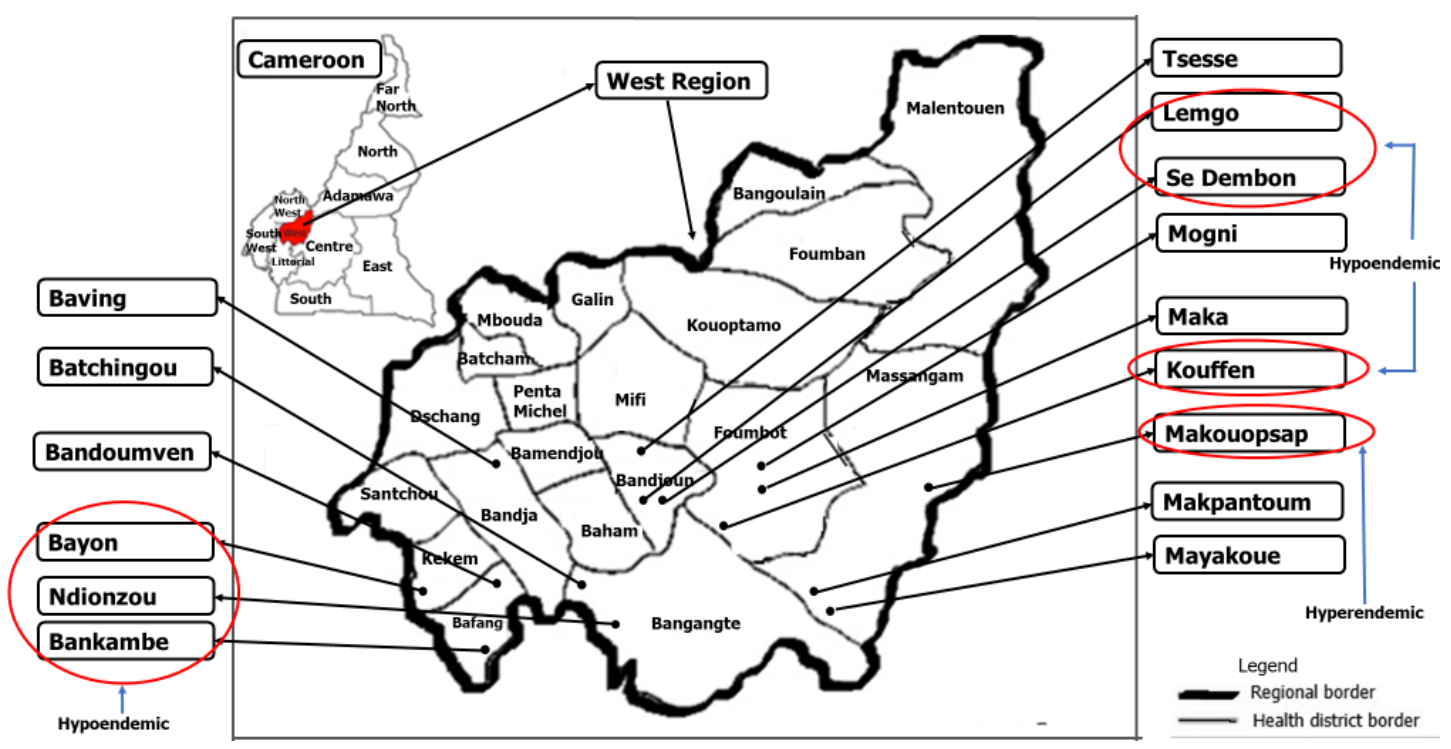

Figure 3. Map of the West Region of Cameroon showing the surveyed communities. The communities were selected based on the prevalence of microfilaria in humans that we reported earlier [12]. 


\subsection{Amplification by $P C R$}

An O-150 PCR (Poolscreen) approach was used. This technique is an up-to-date technique for Onchocerca spp. detection in black flies. It was recently used for the entomological assessment of transmission following recrudescence of onchocerciasis in the Comoé Valley, Burkina Faso [15]. Moreover, the technique has also been employed for the detection of Onchocerca spp. by several authors [5,22,32,36-38]. A set of PCR primers comprising the forward primer, (5'-ATCAATTTTGCAAAATGCG-3') and the reverse primer, (5'-AATAACTGATGACCTATGACC-3') that flank the region of interest in Onchocerca spp. specific gene was used for PCR amplification [14]. Amplification via in silico PCR (http://insilico.ehu.eus/), predicted that there can be a maximum of 4 PCR amplicon, each of length $147 \mathrm{bp}$ at positions 1, 298, 595, and 1189 of the Onchocerca spp. repetitive sequence DNA (GenBank: J04659.1). The PCR was performed using ReadyMix ${ }^{\mathrm{TM}}$ Taq PCR Mastermix (Sigma, Neustadt an der Weinstraße, Germany) in a total volume of $15 \mu \mathrm{L}$. The standard PCR conditions were $95^{\circ} \mathrm{C}$ for $3 \mathrm{~min}$ followed by 35 cycles at $95^{\circ} \mathrm{C}$ for $1 \mathrm{~min}, 45^{\circ} \mathrm{C}$ for $30 \mathrm{~s}$, and $72{ }^{\circ} \mathrm{C}$ for $1 \mathrm{~min}$, with a final extension at $72{ }^{\circ} \mathrm{C}$ for $10 \mathrm{~min}$. Samples that generated a PCR signal on the electropherogram were considered positive. Only samples that were positive after a second independent PCR were reported as confirmed positive. This method was reported to be specific for detecting Onchocerca spp. in pools of black flies and additional purification steps of genomic DNA did not influence the PCR results obtained [14].

\subsection{Data Analysis}

A maximum likelihood approach was applied to estimate the frequency of infection-in the vector population—and the confidence intervals using the algorithms contained in the Poolscreen software [39]. Two sets of analyses were performed to calculate the infection rates in the vector population. These included the frequency of infective black flies—calculated from pools of heads-representing black flies harboring infective L3 larval stage and the frequency of infected black flies, calculated from pools of bodies, representing black flies harboring non-infectious L1 and L2 stages [40]. Chi square test was used to compare the proportions of black flies between the communities. On the other hand, the risk of infective or infected status of black flies was assessed by binary logistic regression using SPSS v26. A $p$-value $<0.05$ was considered statistically significant.

Author Contributions: Conceptualization, project administration, supervision, and funding acquisition: R.N., S.M.G., and J.S.; methodology, C.M.S., J.E.N., F.B.A., R.A.S., and J.K.; formal analysis and data curation, C.M.S. and R.A.S.; writing—original draft preparation, C.M.S.; and writing—review and editing, all authors. All authors have read and agreed to the published version of the manuscript.

Funding: This research was funded by VLIR-UOS, Vrije Universiteit Brussel (SGP027-VLIR368) through the Global Minds Small Great Projects and the Belgian University Cooperation (www.ares-ac.be/fr/cooperation-audeveloppement) through the PRD2013 collaborative research and development project between the "Université Libre de Bruxelles", Belgium, and the University of Buea, Cameroon.

Acknowledgments: The authors thank the fly collectors, the staff of the six health districts, and the community leaders for their cooperation in facilitating the fieldwork.

Conflicts of Interest: The authors declare no conflict of interest. The funders had no role in the design of the study; in the collection, analyses, or interpretation of data; in the writing of the manuscript, or in the decision to publish the results.

\section{References}

1. Shintouo, C.M.; Shey, R.A.; Nebangwa, D.N.; Esoh, K.K.; Nongley, N.F.; Nguve, J.E.; Giron, P.; Mutesa, L.; Vanhamme, L.; Souopgui, J.; et al. In Silico Design and Validation of OvMANE1, a Chimeric Antigen for Human Onchocerciasis Diagnosis. Pathogens 2020, 9, 495. [CrossRef] [PubMed]

2. Njume, F.N.; Ghogomu, S.M.; Shey, R.A.; Gainkam, L.O.T.; Poelvoorde, P.; Humblet, P.; Kamgno, J.; Robert, A.; Mutesa, L.; Lelubre, C.; et al. Identification and characterization of the Onchocerca volvulus Excretory Secretory Product Ov28CRP, a putative GM2 activator protein. PLoS Negl. Trop. Dis. 2019, 13, e0007591. [CrossRef] [PubMed] 
3. Lustigman, S.; Makepeace, B.L.; Klei, T.R.; Babayan, S.A.; Hotez, P.; Abraham, D.; Bottazzi, M.E. Onchocerca volvulus: The Road from Basic Biology to a Vaccine. Trends Parasitol. 2018, 34, 64-79. [CrossRef] [PubMed]

4. Boursou, D.; Ndjonka, D.; Eisenbarth, A.; Manchang, K.; Paguem, A.; Ngwasiri, N.N.; Vildina, J.D.; Abanda, B.; Krumkamp, R.; van Hoorn, S.; et al. Onchocerca-infected cattle produce strong antibody responses to excretory-secretory proteins released from adult male Onchocerca ochengi worms. BMC Infect. Dis. 2018, 18, 200. [CrossRef]

5. Wahl, G.; Ekale, D.; Schmitz, A. Onchocerca ochengi: Assessment of the Simulium vectors in north Cameroon. Parasitology 1998, 116 Pt 4, 327-336. [CrossRef]

6. Hotterbeekx, A.; Ssonko, V.N.; Oyet, W.; Lakwo, T.; Idro, R. Neurological manifestations in Onchocerca volvulus infection: A review. Brain Res. Bull. 2019, 145, 39-44. [CrossRef]

7. World Health Organisation. Onchocerciasis Key Facts. 2019. Available online: https://www.who.int/newsroom/fact-sheets/detail/onchocerciasis (accessed on 28 April 2020).

8. Mounchili, S.C.; Ghogomu, M.A.; Ghogomu, S.M.; Njume, F.N.; Shey, R.A.; Souopgui, J. Analysis of Onchocerca volvulus $\beta$-tubulin gene polymorphism in the Mbonge sub-division of Cameroon: Evidence of gene selection by ivermectin. J. Genet. Mol. Biol. 2018, 2, 1-6.

9. Fobi, G.; Yameogo, L.; Noma, M.; Aholou, Y.; Koroma, J.B.; Zouré, H.M.; Ukety, T.; Lusamba-Dikassa, P.-S.; Mwikisa, C.; Boakye, D.A.; et al. Managing the Fight against Onchocerciasis in Africa: APOC Experience. PLoS Negl. Trop. Dis. 2015, 9, e0003542. [CrossRef]

10. Katabarwa, M.N.; Eyamba, A.; Nwane, P.; Enyong, P.; Kamgno, J.; Kuété, T.; Yaya, S.; Aboutou, R.; Mukenge, L.; Kafando, C.; et al. Fifteen years of annual mass treatment of onchocerciasis with ivermectin have not interrupted transmission in the west region of cameroon. J. Parasitol. Res. 2013, 2013, 420928. [CrossRef]

11. Tekle, A.H.; Zoure, H.G.M.; Mounkaila, N.; Boussinesq, M.; Coffeng, L.E.; Stolk, W.; Remme, J.H. Progress towards onchocerciasis elimination in the participating countries of the African Programme for Onchocerciasis Control: Epidemiological evaluation results. Infect. Dis. Poverty 2016, 5, 66. [CrossRef]

12. Kamga, G.-R.; Dissak-Delon, F.N.; Djeunga, H.N.; Biholong, B.D.; Ghogomu, S.M.; Souopgui, J.; Kamgno, J.; Robert, A. Important progress towards elimination of onchocerciasis in the West Region of Cameroon. Parasites Vectors 2017, 10, 373. [CrossRef] [PubMed]

13. World Health Organisation. Guidelines for Stopping Mass Drug Administration and Verifying Elimination of Human Onchocerciasis; World Health Organisation: Geneva, Switzerland, 2016.

14. Oskam, L.; Schoone, G.J.; Kroon, C.C.M.; Luján, R.; Davies, J.B. Polymerase chain reaction for detecting Onchocerca volvulus in pools of blackflies. Trop. Med. Int. Health 1996, 1, 522-527. [CrossRef] [PubMed]

15. Koala, L.; Nikièma, A.S.; Paré, A.B.; Drabo, F.; Toé, L.D.; Belem, A.M.G.; Boakye, D.A.; Traoré, S.; Dabire, R.K. Entomological assessment of the transmission following recrudescence of onchocerciasis in the Comoe Valley, Burkina Faso. Parasit Vectors 2019, 12, 34. [CrossRef]

16. Bennuru, S.; Oduro-Boateng, G.; Osigwe, C.; Del Valle, P.; Golden, A.; Ogawa, G.M.; Cama, V.; Lustigman, S.; Nutman, T.B. Integrating multiple biomarkers to increase sensitivity for the detection of Onchocerca volvulus infection. J. Infect. Dis. 2019, 221, 1805-1815. [CrossRef] [PubMed]

17. Bakajika, D.; Senyonjo, L.; Enyong, P.; Oye, J.; Biholong, B.; Elhassan, E.; Boakye, D.; Dixon, R.; Schmidt, E. On-going transmission of human onchocerciasis in the Massangam health district in the West Region of Cameroon: Better understanding transmission dynamics to inform changes in programmatic interventions. PLoS Negl. Trop. Dis. 2018, 12, e0006904. [CrossRef] [PubMed]

18. Osei-Atweneboana, M.Y.; Boakye, D.A.; Awadzi, K.; Gyapong, J.; Prichard, R.K. Genotypic analysis of $\beta$-tubulin in Onchocerca volvulus from communities and individuals showing poor parasitological response to ivermectin treatment. Int. J. Parasitol. Drugs Drug Resist. 2012, 2, 20-28. [CrossRef]

19. Kamga, G.-R.; Dissak-Delon, F.N.; Djeunga, H.N.; Biholong, B.D.; Ghogomu, S.M.; Souopgui, J.; Zoure, H.G.M.; Boussinesq, M.; Kamgno, J.; Robert, A. Still mesoendemic onchocerciasis in two Cameroonian community-directed treatment with ivermectin projects despite more than 15 years of mass treatment. Parasit Vectors 2016, 9, 581. [CrossRef]

20. Barbazan, P.; Escaffre, H.; Mbentengam, R.; Boussinesq, M. Entomologic study on the transmission of onchocerciasis in a forest-savanna transition area of Cameroon. Bull. Soc. Pathol. Exot. 1998, 91, 178-182. 
21. Cupp, E.W.; Sauerbrey, M.; Cama, V.A.; Eberhard, M.; Lammie, P.J.; Unnasch, T.R. Elimination of onchocerciasis in Africa by 2025: The need for a broad perspective. Infect. Dis. Poverty 2019, 8, 50. [CrossRef]

22. Higazi, T.B.; Zarroug, I.M.A.; Mohamed, H.A.; ElMubark, W.A.; DeRan, T.C.M.; Aziz, N.; Katabarwa, M.; Hassan, H.K.; Unnasch, T.R.; MacKenzie, C.D.; et al. Interruption of Onchocerca volvulus Transmission in the Abu Hamed Focus, Sudan. Am. J. Trop. Med. Hyg. 2013, 89, 51-57. [CrossRef]

23. Kim, Y.E.; Remme, J.H.; Steinmann, P.; Stolk, W.A.; Roungou, J.B.; Tediosi, F. Control, elimination, and eradication of river blindness: Scenarios, timelines, and ivermectin treatment needs in Africa. PLoS Negl. Trop. Dis. 2015, 9, e0003664.

24. Rebollo, M.P.; Zouré, H.; Ogoussan, K.; Sodahlon, Y.; A Ottesen, E.; Cantey, P.T. Onchocerciasis: Shifting the target from control to elimination requires a new first-step-elimination mapping. Int. Health 2018, 10 (Suppl. 1), i14-i19. [CrossRef] [PubMed]

25. World Health Organisation. Guidelines for Stopping Mass Drug Administration and Verifying Elimination of Human Onchocerciasis, Criteria and Procedures Annexes. 2016. Available online: https://www.who.int/ onchocerciasis/resources/ISBN9789241510011_Annexes.pdf (accessed on 30 May 2020).

26. Eisenbarth, A.; Achukwi, M.D.; Renz, A. Ongoing Transmission of Onchocerca volvulus after 25 Years of Annual Ivermectin Mass Treatments in the Vina du Nord River Valley, in North Cameroon. PLoS Negl. Trop. Dis. 2016, 10, e0004392. [CrossRef] [PubMed]

27. Wilson, M.D.; Post, R.J.; Gomulski, L.M. Multivariate morphotaxonomy in the identification of adult females of the Simulium damnosum Theobald complex (Diptera: Simuliidae) in the Onchocerciasis Control Programme area of West Africa. Ann. Trop. Med. Parasitol. 1993, 87, 65-82. [CrossRef]

28. Dissak-Delon, F.N.; Kamga, G.-R.; Humblet, P.C.; Robert, A.; Souopgui, J.; Kamgno, J.; Ghogomu, S.M.; Godin, I. Barriers to the National Onchocerciasis Control Programme at operational level in Cameroon: A qualitative assessment of stakeholders' views. Parasites Vectors 2019, 12, 246. [CrossRef] [PubMed]

29. Rodríguez-Pérez, M.A.; Danis-Lozano, R.; Rodriguez, M.H.; Unnasch, T.R.; Bradley, J. Detection of Onchocerca volvulus infection in Simulium ochraceum sensu lato: Comparison of a PCR assay and fly dissection in a Mexican hypoendemic community. Parasitology 1999, 119 Pt 6, 613-619. [CrossRef]

30. Rodriguez-Perez, M.A.; Unnasch, T.R.; Lizarazo-Ortega, C.; Domínguez-Vázquez, A.; Mendoza-Herrera, A.; Lilley, B.G.; Segura-Arenas, R.; Reyes-Villanueva, F. Polymerase chain reaction monitoring of transmission of Onchocerca volvulus in two endemic states in Mexico. Am. J. Trop. Med. Hyg. 2004, 70, 38-45. [CrossRef]

31. Rodriguez-Perez, M.A.; Gopal, H.; Adeleke, M.A.; De Luna-Santillana, E.J.; Gurrola, J.N.; Guo, X. Detection of Onchocerca volvulus in Latin American black flies for pool screening PCR using high-throughput automated DNA isolation for transmission surveillance. Parasitol. Res. 2013, 112, 3925-3931. [CrossRef]

32. Guevara, A.G.; Lilley, B.G.; Rumbea, J.; Unnasch, T.R.; López, A.; Collins, R.; Vieira, J.C.; Katholi, C.R.; Vieira, N. Entomological evaluation by pool screen polymerase chain reaction of Onchocerca volvulus transmission in Ecuador following mass Mectizan distribution. Am. J. Trop. Med. Hyg. 2003, 68, 222-227. [CrossRef]

33. Karija Vlahović, M.; Kubat, M. DNA extraction method from bones using Maxwell ${ }^{\circledR}$ 16. Leg. Med. 2012, 14, 272-275. [CrossRef]

34. Gopal, H.; Rodríguez-Pérez, M.A. Purification of O. Volvulus gDNA from S. Ochraceum s.l. Black Fly Head or Body Pools Using the Maxwell ${ }^{\circledR} 16$ Instrument. 2010. Available online: https://worldwide.promega.com/resources/pubhub/purification-of-o-volvulus-gdna-from-s-ochraceumsl-black-fly-using-the-maxwell-16-instrument/\#ArticleBody-e114f3eb-e9ed-4cb7-bc15--1ccd1036850a (accessed on 29 May 2020).

35. Gutiérrez-López, R.; La Puente, J.M.-D.; Gangoso, L.; Soriguer, R.C.; Figuerola, J. Comparison of manual and semi-automatic DNA extraction protocols for the barcoding characterization of hematophagous louse flies (Diptera: Hippoboscidae). J. Vector Ecol. 2015, 40, 11-15. [CrossRef] [PubMed]

36. Richards, F., Jr.; Klein, R.; Rios, D.; Valdez, C.G.C.; Cupp, E.; Dominguez, A.; Hassan, H.K.; De Leon, O.; Espinoza, C.E.D.; Monroy, Z.M.; et al. One Hundred Years After Its Discovery in Guatemala by Rodolfo Robles, Onchocerca volvulus Transmission Has Been Eliminated from the Central Endemic Zone. Am. J. Trop. Med. Hyg. 2015, 93, 1295-1304. [CrossRef] [PubMed] 
37. Higazi, T.B.; Zarroug, I.M.A.; Mohamed, H.A.; Mohamed, W.A.; DeRan, T.C.M.; Aziz, N.; Katabarwa, M.; Hassan, H.K.; Unnasch, T.R.; MacKenzie, C.D.; et al. Polymerase chain reaction pool screening used to compare prevalence of infective black flies in two onchocerciasis foci in northern Sudan. Am. J. Trop. Med. Hyg. 2011, 84, 753-756. [CrossRef] [PubMed]

38. Marchon-Silva, V.; Caër, J.C.; Post, R.J.; Maia-Herzog, M.; Fernandes, O. Detection of Onchocerca volvulus (Nematoda: Onchocercidae) infection in vectors from Amazonian Brazil following mass Mectizan distribution. Mem. Inst. Oswaldo Cruz 2007, 102, 197-202. [CrossRef] [PubMed]

39. Katholi, C.R.; Toé, L.; Merriweather, A.; Unnasch, T.R. Determining the prevalence of Onchocerca volvulus infection in vector populations by polymerase chain reaction screening of pools of black flies. J. Infect. Dis. 1995, 172, 1414-1417. [CrossRef] [PubMed]

40. Rodriguez-Perez, M.A.; Katholi, C.R.; Hassan, H.K.; Unnasch, T.R. Large-scale entomologic assessment of Onchocerca volvulus transmission by poolscreen PCR in Mexico. Am. J. Trop. Med. Hyg. 2006, 74, 1026-1033. [CrossRef]

(C) 2020 by the authors. Licensee MDPI, Basel, Switzerland. This article is an open access article distributed under the terms and conditions of the Creative Commons Attribution (CC BY) license (http://creativecommons.org/licenses/by/4.0/). 